\title{
Learning Pelvic Examination with Professional Patients
}

\author{
Shrestha S, ${ }^{1}$ Wijma B, ${ }^{2}$ Swahnberg K, ${ }^{3}$ Siwe $K^{4}$ \\ 'Kakani Primary Health Centre, Nuwakot, Nepal, ${ }^{2,3}$ Division of Gender and Medicine, Department of Clinical and Experimental \\ Medicine, Faculty of Health Sciences, Linköping University, Linköping, Sweden, 'Department of Obstetrics and Gynecology, \\ University Hospital, Linköping, Sweden and Gender and Medicine, Department of Clinical and Experimental Medicine, Linköping \\ University, Sweden.
}

\section{ABSTRACT}

Performing pelvic examination is a vital skill to learn during gynecological and obstetrical training. It's a difficult maneuver to master as there is very little to see and more to feel and interpret. In addition, learning PE in usual clinical set-up has been found to induce lot of stress and anxiety among both the patients and the students. Students fear of hurting the patients and being judged inept, whereas patients feel embarrassed having to expose their most intimate body parts for learning purpose. This hampers effective learning. Learning PE on sedated women before surgery or on mannequins has been practiced as alternative learning models. But, they have been found to miss out on teaching the communication skills, which are as important as the palpation skills. However, there exists another model of learning PE - the professional patients, who are specially trained to act as patients and also guide the students on how to make a proper PE. They provide stress-free environment for the students to learn PE and at the same time, provide immediate feedback on each of their maneuvers. They form a complete learning model and help students to see patients as partner and not just a person seeking help.

Key Words: learning model, pelvic examination, stress, students

\section{INTRODUCTION}

Clinical skills are the most valuable asset for a clinician to acquire. Yet, that is a tricky goal to achieve in medical education. Unlike clinical knowledge, learning clinical skills needs a great deal of participation and help from another group of people than teachers, i.e. patients, who in fact don't have any obligation to teach - as they come to health care because they need to get help. There seems to be no good alternative to patients when it comes to learning examination skills. Still, using patients as a learning tool is ethically inappropriate, even if it means no direct harm to them. The reason is that it easily becomes an exploitation of their subordinate position, as they need help. On top of that, if learning
Correspondence:

Dr. Suvash Shrestha

Kakani Primary Health Center

Nuwakot, Nepal.

Email: suvashsht@gmail.com

Phone: 9841932220 
is about examining intimate parts of the body like sexual organs, the learning process suddenly becomes awkward, complicated and difficult. But, this should not mean that students be left untaught about such skills.

\section{What is so special about PE?}

Pelvic examination (PE) includes a speculum and a bimanual examination of the female reproductive organs. A PE is an encounter between two individuals with different ideas and knowledge. One is the gynecologist, for whom it might be a routine procedure. The other one is the female patient who might not have the same feelings about the PE. She has to expose the most intimate parts of her body to an unknown person for a procedure, about which she has very vague ideas.

Studies have shown that a majority of women have negative perceptions and experiences of the PE. ${ }^{1,2}$ In one study, almost half of the women participants felt embarrassed and apprehensive during a PE and considered the speculum examination more uncomfortable than the bimanual palpation. ${ }^{1}$ The first PE remains very crucial as it determines attitudes towards subsequent PEs. ${ }^{2}$ Facing their first PE, women worried about how they would manage, felt embarrassed about getting undressed, were anxious and anticipated pain. ${ }^{3,4}$ Likewise, the gender of the examiner is a concern for many women. In one study women reported that going through a PE was more embarrassing, but not more painful, with a male than a female examiner. ${ }^{5}$

Many women prefer privacy and don't even want attendants. ${ }^{6-8}$ Studies have shown that a majority of women prefer not to have students participating in their PEs. ${ }^{9,10}$ One study also reported that $63 \%(60 / 96)$ of female participants wished not to have a PE performed by a student and one third (32/96) identified it as a concern if the examination involved a male student. ${ }^{10}$ Thus, even a routine PE may incite much stress among patients and intruding students to the PE sessions could add more distress to the patients.

\section{Hurdles towards efficient learning}

As a matter of fact, it is not easy for the students either. The intimate nature of the PE makes many of them, especially males, very uncomfortable ${ }^{11}$ and reluctant to perform the PE. They feel anxious and embarrassed. They may also be afraid of hurting the patient, who might not complain about it due to her subordinate position. One study even found that students' expectations about performing their first PE were dominated by fears of hurting the patient, being judged inept and unable to recognize pathology, getting sexually aroused, finding the examination unpleasant and therefore disturbing the doctor-patient relationship. ${ }^{12}$ In such a stressful environment, the students' capacity to learn the complex tasks of examining and palpating will be seriously hampered.

Another problem for students is to get time enough to examine a patient for learning purpose. Especially when there are many students, tutors find it hard to encourage students to perform a PE and explain the details of the techniques, due to fear of further embarrassing the patient. Besides, students need to have very good communication skills to persuade the patient to let them examine. Unfortunately, students are yet to acquire such good skills, and thus missing their opportunity to learn performing the PE.

Even technically, palpation part of the PE is a complex maneuver to master as there is very little to be visually demonstrated. Instead, the information from palpating builds on haptic perception and its correct interpretation. It requires a well trained visual imagination capacity to create a three dimensional picture of what one palpates bimanually and much experience to be able to interpret the findings correctly.

Thus, loaded with so many obstacles, learning PE is definitely a tricky and complicated process. But, at the same time, much effort has been made to create a less stressful learning situation in which patient care is not compromised.

\section{Different ways of learning PE}

In many countries, students learn how to perform a PE on sedated or anesthetized women before surgery ${ }^{13-15}$ or on mannequins ${ }^{16}$ or on a clinical patient during their ordinary clinical visits, while supervised by a tutor. But, each of these three models has their own problems.

Sedated women have relaxed pelvic muscles, which facilitate the palpation of pelvic organs, and the students do not have to fear about inflicting pain to the patient. But on the other hand, examining unconscious patients fails to teach those communication skills which are as essential as the technical skills. Only with good communication skill can the students make clinical patients in future relaxed enough for a proper PE. Moreover, most of such examinations are performed without the patient's informed consent, which in itself is a highly unethical practice. ${ }^{7,13,15}$ It also silently gives an impression to the students that unethical procedures may be allowed if done undercover. This is again an unethical teaching practice.

Mannequins and electronic simulators do not induce ethical complications and can be used for repeated practices, until the students master the techniques of examination. Some of these technical devices even 
provide immediate feedback as to what organs the examiner has palpated. ${ }^{16}$ But similar to sedated women, these devices are also handicapped; as they can't teach students how to approach the patient in such a way that she will feel comfortable and be able to follow instructions like relax her muscles enough to allow the palpation maneuvers.

It seems probable that there could be no better alternative to teach PE than the patients themselves. Only they could make a complete teaching model, which could teach both examination and communication skills. At the same time, they put students in a real life like situation, thus preparing them better for the actual clinical setting. But it remains a big challenge to use patients for teaching purpose without compromising their care in any way. Maybe some well educated women could volunteer to act as patients and help students learn? "Professional patients" (PP) could in fact constitute a perfect and complete teaching model.

\section{Professional patients}

The history of PPs goes back to 1960s, when R Kretzschmar from the US, felt that the existing way of teaching PE was not effective. ${ }^{17}$ He therefore developed a medical interview instruction program in which a group of motivated women were trained to simulate having gynecologic complaints. Medical students were to interview them, and the result was later critically analyzed in a post interview session. The same women were later trained to guide the students in how to perform the PE while being examined themselves. Thus, the concept of professional patients for teaching PE emerged. Currently, the US, the Netherlands, Sweden, Australia, the United Kingdom, and Belgium are using it in different forms. ${ }^{18}$

There is no generally accepted protocol to follow in a professional patient teaching model. Each country and faculty may have its own model that suits its socioeconomic and educational system. With my personal experience, I noticed a very well constructed PP model in Linkoping University (LiU), Sweden. As an exchange student from Kathmandu Medical College, I got to attend different clinics in LiU and one particular thing that struck me very hard was the PP model for learning PE.

\section{Professional patient model for learning the PE at Linkoping University (LiU), Sweden}

At LiU, the model was introduced by Professor Barbro Wijma in 1982 and has been running very effectively since then, from 1989 with Dr. Karin Siwe as coordinator. The professional patients at LiU are healthy, specially trained women who voluntarily allow medical students, student midwives and residents in gynecology to perform a PE on them. During the examination, they coach the students in how to perform PE. Usually, the PPs are aged 35 - 55, are comfortable with their bodies and the PE procedure, are easy to examine and have good interpersonal and communication skills. They may have various occupations - school teacher, social worker, nurse, midwife, administrative staff, and others. ${ }^{18}$

Recruitment of "suitable" women is the foundation of a successful teaching model. Usually, the coordinator of the program approaches those women who show interest in becoming a PP. The woman gets detailed information on the outline of the program, its objectives, her role as a PP, as well as advantages and possible difficulties of being a PP. When recruited, the woman is paid 70 Euros per working session (2-3 hours).

A woman who agrees to join the program is familiarized with other women who are already working as PPs. She attends one PE teaching session to observe how it is done. Later, the coordinator examines her to find out whether she is bodily suitable to become a PP. While going through this $\mathrm{PE}$, she is offered a mirror to let her see her external genitals and the vagina and portio, and to help her follow what is being done. She is taught how it feels when her inner genital organs are palpated. She also joins lessons about anatomy and physiology of female reproductive organs, facts about some common gynecological disorders, and the Swedish wording for all the anatomical parts that might be mentioned. She also gets instructions about what kind of communication that she is supposed to have with the students. Later, she watches a video prepared by the organizers: "The Pelvic Examination Step by Step" ${ }^{19}$ and/or "Learning the Pelvic Examination" . ${ }^{20}$ On these videos each and every step of the PE is demonstrated, while the examiner is keeping proper communication with the patient. With this training the new professional patient gets ready to take on her role as an instructor.

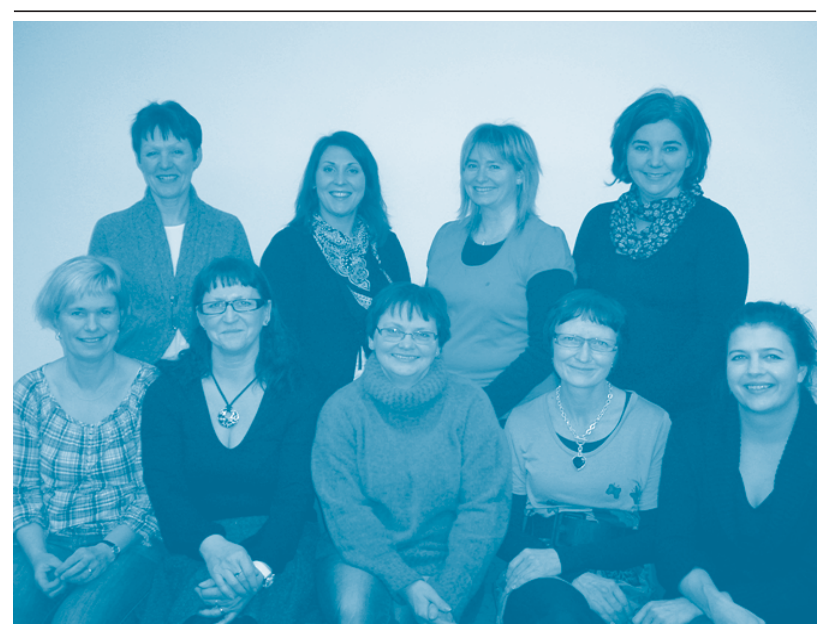

Figure 1. Group of professional patients working at LiU 


\section{Learning sessions with PPs}

At the medical faculty, LiU, medical students attend a PE learning session with PPs twice during their undergraduate training. They perform bimanual palpation of the uterus during the fourth semester, and a complete PE with instruments and bimanual palpation of uterus and adnexa during the eleventh semester. ${ }^{18}$

During the fourth semester, a gynecologist gives a lecture on interpersonal and technical skills involved in performing a $P E$, in which communication skills are emphasized. One major purpose is to inspire the students to acknowledge the patient as a partner and not just a patient. Traditionally, a patient is supposed to have a subordinate role and follow the examiner's instructions passively. But, as a partner, the patient has an equally important role as the examiner. She decides the course of examination. She is free to tell what feels good to her, what feels painful and what she thinks would be a better way to palpate. With active participation, she helps the examiner to make a better examination.

The gynecologist then demonstrates a PE on a plastic model of uterus and adnexa. Later, the students watch the video "The Pelvic Examination Step by Step" .19,20 They are also given a booklet, which summarizes the content in the video.

Finally, students attend a group learning session with PPs. Each group has two PPs, six students and a gynecologist. Initially, they all sit down for an introductory talk to get to know each other and make the students feel at ease. The gynecologist explains the objectives of the session, how the students should approach a woman during a $P E$, and what the rules of the session are (e.g. there is time enough to palpate until the students feel sure of what they have in their hands, the PPs will give feed-back whenever something unpleasant occurs, the students may try out exactly how deep they need to place their external hand). During the session, the gynecologist first performs PE on one of the PPs, exactly following the instructions in the booklet. She specifically stresses those steps where a beginner can go wrong like e.g. the correct grips of the instruments, or adequate use of both hands. Later supervised by the gynecologist, the PPs then take on their role as an instructor from the patient's position and guide the student in how to find the uterus by giving continuous informative feed-back. Each student is encouraged to take the time needed to make sure she/he has clearly been able to examine the uterus, as to size, position, consistency, smoothness, tenderness, and mobility.

When all students have performed the PE, everyone again sits down for a post-examination evaluative talk. The students then have the opportunity to discuss any difficulties they faced during the examination or any other kind of queries they have.

During the second PE session during the eleventh semester, the students watch the video again and attend a learning session, now in groups of four students but similar to the one they attended before. This time, they perform a complete examination - a speculum examination, bimanual examination of uterus, ovaries and pouch of Douglas. After this session, the students start their four weeks of gynecological clinical clerkship, where they try to perform as many PEs as they can, under the supervision of a gynecologist.

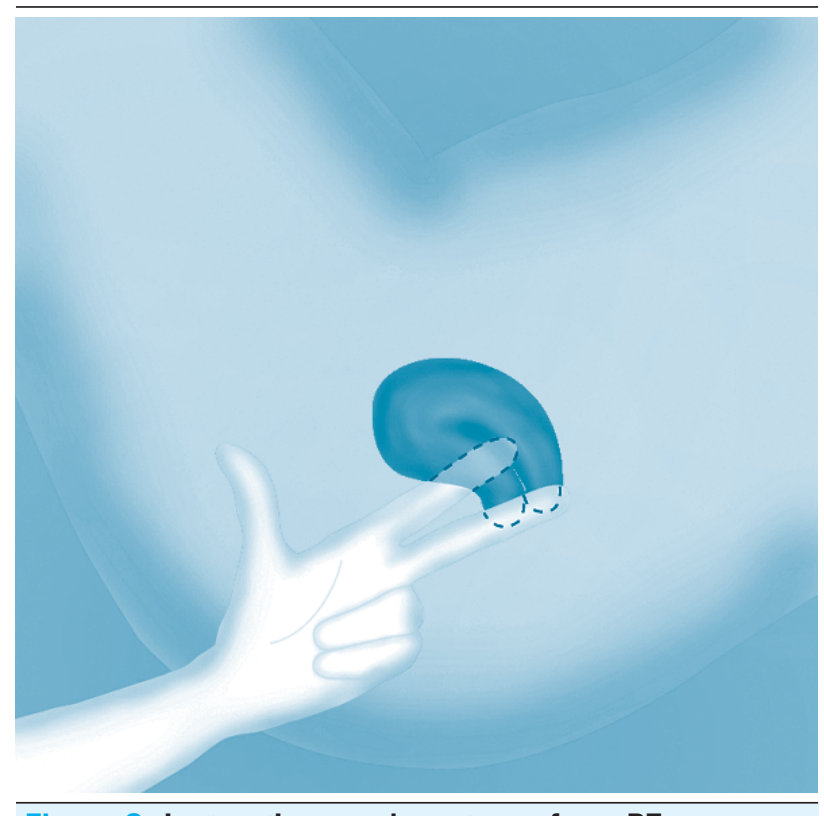

Figure 2. Instructions on how to perform PE

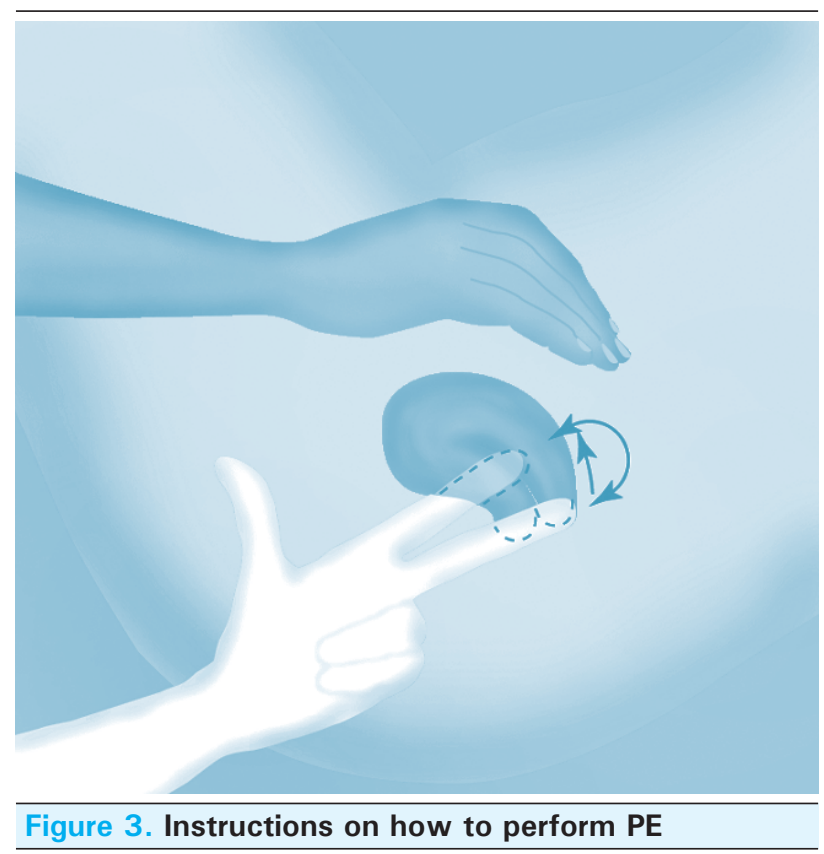




\section{DISCUSSION}

\section{Advantages of PP model}

Many studies have proved a high efficiency of the PP model as to students' learning to perform a PE. Siwe et al compared the skills acquired by two groups of medical students who were trained either with PPs or with clinical patients $(\mathrm{CP})$ in gynecology clinics. ${ }^{21}$ During the learning sessions, almost all students in the PP model were certain that they had palpated the uterus and at least one ovary. These students were also less distressed after having performed their first PE than students who had been instructed using the CP model. Likewise, another study by Kleinman et al showed that PP trained students had better interpersonal skills than the physician-trained students, although no difference was found in their technical skills. ${ }^{22}$ Better interpersonal communication skills among PP model trained students than the conventionally taught students have also been reported in other studies. ${ }^{23,24}$

Stress, risks of unethical conduct, problem with interpreting haptic perception findings, and time constraints are the major hurdles towards effective PE learning. It is really commendable how PPs can ease out all those problems. They make students feel at ease and provide them with concrete hints on how to approach the patient in an ethically good way, how to understand bodily signs of discomfort even when she does not complain, and how to make her relax and feel comfortable.

Once a student knows that the PP is there to help him/her, all the fears of hurting the patient, being judged inept, or taking a too long time to examine decrease. Often a student will feel as if a huge burden is lifted off his/her shoulder. The learning environment becomes very conducive and friendly. Only under such circumstances, the students could focus on the procedure and the different maneuvers to be undertaken. The stress level will probably be low enough to allow learning the very complex task of palpating: performing the correct movements with two hands at a time while watching out so the patient is not hurt, perceiving what is between the hands by means of haptic perception, interpreting the findings and getting words to express them.

Another charm of the PP model is the immediate feedback the students get about their maneuvers. When learning the PE in a clinical setting from regular patients, a student would never know if he/she is doing it right or wrong, pressing hard enough or not, hurting the patient or not, inserting the speculum in the right way or not, or holding the instruments correctly or not. Neither can the gynecologist comment on the students' performance, as their fingers are inside the patient's body. Even the patient cannot help because she does not have any idea what so ever about the procedure and how it should have felt during an ideal examination. So, only the trained patients can give correct feed-back on the students' performance.

Often, it is said that good clinical skills can be acquired only after years and years of practice, and that there is no shortcut. Well, there definitely may not be shortcuts, but performing the first PE in the right way with constructive feedback will definitely help to hone one's skills in a short period of time.

Moreover, PPs teach students to acknowledge patients as partners from whom they have much to learn, instead of merely patients seeking help. A consultation gives best results only when the doctor and the patient stand on equal levels as partners, not when the doctor dominates over the patient, as in a conventional doctor-patient relationship.

When all focus is on students and their learning, it is easy to overlook the perspective of the PPs. But the PP model has also been found beneficial for the PPs. In a study by Siwe et al, PPs reported that they acquired increased knowledge about their bodies. They had also got a higher self-esteem from their teaching experiences, when having realized that their knowledge highly contributed to the student's learning, which made them feel proud. ${ }^{25}$

\section{Weaknesses of PP model}

Probably no one would argue against the fact that although the PE follows a fixed set of steps, it has to be tailored for each and every patient. The maneuvers have to be modified depending upon the physical built and age of the patient. Of course, the anatomy of a teenage girl would not be exactly the same as that of a woman approaching the menopause. The findings when palpating the reproductive organs would not be the same. Whereas the PPs are mostly older than 35 years of age, it remains a big question, whether the students could utilize their learning from a 35 year old woman when they are to examine a 19 year old adolescent. Thus, although the PPs provide students with an overall guide on how to perform a $\mathrm{PE}$, there are still some learning gaps left for the students to fill for themselves.

Another weakness of this model could be its inability to teach students the abnormal examination findings. As all the PPs have normal anatomy, students, in this session, will not learn about abnormal findings. It may be argued, 
though, that knowing what a normal palpation finding is like, is a prerequisite for being able to diagnose any abnormality. Besides, teaching abnormal findings is definitely not the scope of the PP model, the aim of which merely is to teach the technical and communication skills involved in performing the PE.

The other concern is how well the PPs prepare the students for real life scenarios. Since the PPs create an extremely friendly environment during PE, students might find it difficult to adapt to real clinical scenarios, where different types of patients show up, of whom some may be very hard to deal with. Their examination definitely would not be as easy and stress free as that of the PPs. Thus, it needs a lot of thinking - do the PPs put the students in a position they would face when they actually begin their career? But, since the students also do clinics besides the sessions with PPs, this should not be a problem.

Finally, there is always an ethical issue, whenever human beings, or even animals, are used for teaching and research purposes. There could be an argument over the identity of the PPs. Should the college faculty adjudge them as its staff members and openly provide information about them as any other staff member? Or, should the faculty try to keep them veiled - just like medical journals, when they use an individual's picture in publication, try not to reveal his or her identity. There indeed is a very narrow line between what is ethical and what is unethical.

\section{Difficulties in sustaining a PP teaching model}

There are certain problems in the sustenance of this model. One is of course the availability of PPs. It is a big step for a woman to become a PP. She needs to have good motivation and a determination to let her most private and intimate organs be used for learning purposes. On the top, how would her family members view her decision to become a PP? Will her children and husband accept it? Will she be okay talking about her work with her friends as if it is just like any other job? There may be many social constraints a woman has to overcome, if she is to become a PP. Therefore, it may be hard to get a sufficient number of PPs. Another problem is that they might leave the program for various reasons, e.g. gynecological problems, postmenopausal complaints, or moving from town. So, a continuous supply of PPs has to be maintained to keep this teaching model going, which is a considerable piece of work - but crucial to keep the program running. Costs and economic sustenance are other crucial parts that need to be firmly established in the educational system.

\section{Learning PE in Nepal}

Nepal has a very different socio-economic situation from many western countries. In 2004, it had an adult female literacy rate of only approximately $35 \% .{ }^{26}$ Issues related to sex are highly restricted topics even in the most developed parts of the country, and the concept of having a $P E$ is a social taboo. Getting undressed and exposing her most private body parts to a stranger would be the most daunting and stressful act for a female patient, let alone the anticipation of pain and harm to the body. Under such circumstances, getting active participation from the patient is simply next to impossible.

Learning PE in Nepal is also different. Students join medical officers, residents and gynecologists in their clinics. There, they observe their seniors perform one or two PEs. Mostly after the PE and after the patient has left, the gynecologist or senior medical officer describes how to perform the PE and what findings the student should be aware of. As the next patient comes, the students would then get to try. Very rarely someone cares to inform the patient that the examiner is a student who wants to learn PE. Consent is not a thing to ask for; it is usually taken for granted. During the PE, the student usually has to act as if he/she knows the procedure well, so the patient would not have any idea that she is being used for learning purpose. To keep things neat, no one - neither the tutor nor the student - interacts with the patient while performing the exam, except for occasional instructions to the patient to take deep breaths, spread her legs apart and relax her pelvic muscles. The tutor would not correct the student's wrong maneuvers during the examination, to avoid the patient recognizing that the examiner is a student. Most of the times, in an attempt to disguise oneself as a well learnt doctor; students mimic the way their teachers do it, which means doing the examination fluently and quickly. So, in the end, the student does not even make a complete examination.

With such a background, it is essential to introduce a proper teaching system in Nepal, while at the same time; it might prove a Herculean task to start off with PPs.

\section{PP model for Nepal}

As Nepal offers a very different social context from most of the western world, the LiU model of PPs might not be the most appropriate one for Nepal. The biggest hurdle would definitely be finding motivated women who would take up the position of PPs. Even if someone stands up, she might have to face objections from her family, and even the society.

The concept of PPs is entirely a new one, also for the medical professionals, and might thus incite different reactions. Some may be skeptic about PPs' efficiency. Some might have different opinions about how to conduct the model and how to train the PPs. Therefore a very 
careful and meticulous planning has to be made before taking any steps towards its implementation.

The first step would be to prepare material, like a video and booklets explaining the details of the PE. It would be better to have all the faculty members contribute, so that a consensual and quality resource could be prepared. The faculty members should also work together to develop a training manual for the PPs - how the ordinary women could be trained to become PPs. Active participation and support from all the faculty members would be very crucial to get the concept approved by the university and to get women motivated enough to become PPs.

The concept of learning the PE should be included in the curriculum, thus becoming officially recognized as an obligate part of medical studies. As such, the PE skills should also be examined at a regular or irregular basis to make students understand the necessity to learn the procedure. Along with this, the model must have the clear support from the faculty, implying that any woman who agrees to become a PP should receive great respect as a teacher within the faculty and should be paid accordingly.
To get the ball rolling, may be the model Kretzschmar ${ }^{17}$ once used could be taken advantage of: some interested women are trained to act as patients with certain disorders, students learn to interact with them, i.e. take their history and develop good communication skills. Later, according to the response from students and volunteers, the program could be expanded to include learning to perform the PE. Performing regular student evaluations of the new PP curriculum might help to convince those faculty members that are hesitant to introduce the model. Having the pioneering volunteers in Nepal meeting Swedish PPs and learning how proud these PPs are to master a highly valued teaching skill would certainly add to the probability that the Nepalese model would become reality.

\section{CONCLUSIONS}

The PP model for learning PEs is definitely beneficial for students and has been practiced in many parts of the world. The model provides a low stress environment where students can easily and in a good way train how to perform PE and at the same time interact with the patient. This makes students better prepared when they start their career. A similar teaching model would be very useful in Nepalese medical education system.

\section{REFERENCES}

1. Vella PV. A survey of women undergoing a pelvic examination. Aust N Z J Obstet Gynaecol. 1991;31(4):355-7.

2. Wijma B, Gullberg $M$, et al. Attitudes towards pelvic examination in a random sample of Swedish women. Acta Obstet Gynecol Scand. 1998;77(4):422-8.

3. Larsen SB and Kragstrup J. Experiences of the first pelvic examination in a random samples of Danish teenagers. Acta Obstet Gynecol Scand. 1995;74(2):137-41.

4. Oscarsson MG, Benzein EG, et al. The first pelvic examination. J Psychosom Obstet Gynaecol. 2007;28(1):7-12.

5. Moettus A, Sklar D, et al. The effect of physician gender on women's perceived pain and embarrassment during pelvic examination. Am J Emerg Med. 1999;17(7):635-7.

6. Buchta RM. Adolescent females' preferences regarding use of a chaperone during a pelvic examination. Observations from a private-practice setting. J Adolesc Health Care. 1986;7(6):40911.

7. Fiddes $\mathrm{P}$, Scott $\mathrm{A}$, et al. Attitudes towards pelvic examination and chaperones: a questionnaire survey of patients and providers. Contraception. 2003;67:313-7.

8. Gupta S, Hogan R, and Kirkman RJ. Experience of the first pelvic examination. Eur J Contracept Reprod Health Care. 2001;6(1):348.

9. Mavis B, et al. Medical students' involvement in outpatient clinical encounters: a survey of patients and their obstetriciansgynecologists. Acad Med. 2006;81(3):290-6.

10. Fortier AM, et al. The acceptance of medical students by women with gynaecology appointments. J Obstet Gynaecol Can. 2006;28(6):526-30.

11. Akkad A, Bonas S, et al. Gender differences in final year medical students' experience of teaching of intimate examinations: a questionnaire study. BJOG. 2008;115(5):625-32.

12. Buchwald J. The first pelvic examination: helping students cope with their emotional reactions. J Med Educ. 1979;54(9):725-8.

13. Wilson RF. Unauthorized practice: teaching pelvic examination on women under anesthesia. J Am Med Womens Assoc. 2003;58(4):217-20; discussion 221-2.

14. Wolfberg AJ. The patient as ally--learning the pelvic examination. N Engl J Med. 2007;356(9):889-90. 
15. Schniederjan S and Donovan GK. Ethics versus education: pelvic exams on anesthetized women. J Okla State Med Assoc. 2005;98(8):386-8.

16. Pugh CM, Srivastava S, et al. The effect of simulator use on learning and self-assessment: the case of Stanford University's E-Pelvis simulator. Stud Health Technol Inform. 2001;81:396400.

17. Kretzschmar RM. Evolution of the Gynecology Teaching Associate: an education specialist. Am J Obstet Gynecol. 1978;131(4):367-73.

18. Siwe K. Learning the Pelvic Examination. PhD Thesis. Div of Gender and Medicine, Dept of Clinical and Experimental Medicine, Faculty of Health Sciences. Linköping, Sweden: Linköping University; 2007. Availbale from: http:/ / urn.kb.se/ resolve?urn=urn:nbn:se:liu:diva-10272.

19. Wijma B and Holmer A. The pelvic examination step by step. Linköping: Instruction videotape, Linköping, Mediacenter; 1995.

20. Siwe K. Learning the Pelvic Examination. Instructional DVD. Linköping: University Hospital and FHS, Linköping University, Linköping, Sweden, Media Center, TVB AB, Vreta Kloster, Sweden. anders@mediacenter.tvb.se; 2010
21. Siwe K, Wijma K, Stjernquist M, Wijma B. Medical students learning the pelvic examination: Comparison of outcome in terms of skills between a professional patient and a clinical patient model. Patient Educ Couns. 2007;68(3):211-7.

22. Kleinman DE, Hage ML, et al. Pelvic examination instruction and experience: a comparison of laywoman-trained and physician-trained students. Acad Med. 1996;71(11):1239-43.

23. Holzman GB, Singleton D, et al. Initial pelvic examination instruction: the effectiveness of three contemporary approaches. Am J Obstet Gynecol. 1977;129(2):124-9.

24. Livingstone RA and Ostrow DN. Professional patient-instructors in the teaching of the pelvic examination. Am J Obstet Gynecol. 1978;132(1):64-7.

25. Siwe K, Wijma B, et al. A stronger and clearer perception of self'. Women's experience of being professional patients in teaching the pelvic examination: a qualitative study. BJOG. 2006;113(8): 890-5.

26. ILO. Nepal. 2005 [cited 2010 Jan 16]; Available from: http://www.ilo.org/public/english/region/asro/bangkok/ skills-ap/skills/nepal_literacy.htm. 